\title{
Fabrication, Characterization, and Application of a Composite Adsorbent for Simultaneous Removal of Arsenic and Fluoride
}

\author{
Chuanyong Jing, ${ }^{* \dagger}{ }^{\dagger}$ Jinli Cui, ${ }^{\dagger}$ Yuying Huang, ${ }^{\ddagger}$ and Aiguo $\mathrm{Li}^{\ddagger}$
}

${ }^{\dagger}$ State Key Laboratory of Environmental Chemistry and Ecotoxicology, Research Center for Eco-Environmental Sciences, Chinese Academy of Sciences, Beijing 100085, China

${ }^{\ddagger}$ Shanghai Synchrotron Radiation Facility, Shanghai Institute of Applied Physics, Chinese Academy of Sciences, Shanghai 201214, China

\section{Supporting Information}

ABSTRACT: Coexisting arsenic (As) and fluoride (F) in groundwater poses severe health risks worldwide. Highly efficient simultaneous removal of As and $\mathrm{F}$ is therefore of great urgency and high priority. The purpose of this study was to fabricate a novel composite adsorbent and explore the mechanism for concurrent removal of $\mathrm{As}(\mathrm{V})$ and $\mathrm{F}$ at the molecular level. This bifunctional adsorbent with titanium and lanthanum oxides impregnated on granular activated carbon (TLAC) exhibits a pronounced $\mathrm{As}(\mathrm{V})$ and $\mathrm{F}$ adsorption capacity over commercially available iron- and aluminumbased adsorbents for synthetic and real contaminated ground-

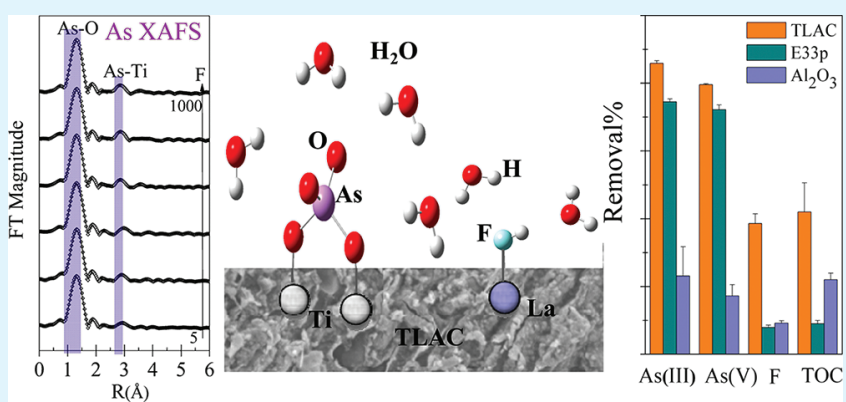
water samples. Synchrotron-based X-ray microfluorescence analysis demonstrates that La and $\mathrm{Ti}$ were homogeneously distributed on TLAC. Extended X-ray absorption fine structure spectroscopic results suggest that As(V) formed bidentate binuclear surface complex as evidenced by an averaged $\mathrm{Ti}-\mathrm{As}$ bond distance of $3.34 \AA$ in the presence of F. Adsorption tests and Fourier transform infrared spectroscopy analysis indicate that $\mathrm{F}$ was selectively adsorbed on lanthanum oxides. The surface configurations constrained with the spectroscopic results were formulated in the charge distribution multisite complexation model to describe the competitive adsorption behaviors of $\mathrm{As}(\mathrm{V})$ and $\mathrm{F}$. The results of this study indicate that TLAC could be used as an effective adsorbent for simultaneous removal of As(V) and F.

KEYWORDS: arsenic, fluoride, simultaneous removal, synchrotron-based techniques, molecular level mechanisms

\section{INTRODUCTION}

Arsenic (As) and fluoride (F) are naturally occurring groundwater contaminants around the world, and have been the focus of extensive research efforts in the past few decades. $^{1-3}$ Coexistence of As and $\mathrm{F}$ in groundwater is commonly found in many countries including Argentina, ${ }^{4}$ China, ${ }^{5}$ Mexico, ${ }^{6}$ and Pakistan, ${ }^{7}$ with concentrations up to 5300 $\mu \mathrm{g}$ of $\mathrm{As} / \mathrm{L}$ and $29 \mathrm{mg}$ of $\mathrm{F} / \mathrm{L}$ in the same groundwater sample. ${ }^{4}$ The synergistic adverse effects are observed in mouse liver and kidney even at low As and F concentrations. ${ }^{8}$ The neuropsychological tests demonstrate that coexposure to As and $\mathrm{F}$ could exacerbate children's performance. 9 The drinking water standards for As and $\mathrm{F}$ are $10 \mu \mathrm{g} / \mathrm{L}$ and $1.5 \mathrm{mg} / \mathrm{L}$, respectively, as suggested by the World Health Organization (WHO). ${ }^{10}$ However, this WHO standard is still a worldwide challenge, especially in rural villages without proper treatment. ${ }^{1}$

Among various As and $\mathrm{F}$ removal technologies, adsorption is most attractive because it is highly efficient, cost-effective, and suitable for single families and small communities. ${ }^{11,12}$ Many adsorptive media have been successfully developed to remove As or F. For example, $\mathrm{TiO}_{2}$ has been recently used for As removal from drinking water ${ }^{11}$ and from wastewater. ${ }^{13}$ Metal impregnation on porous materials has demonstrated promising results. The iron impregnated granular activated carbon (GAC) has an As adsorption capacity of $6.6 \mathrm{mg} / \mathrm{g}$. ${ }^{14}$ To selectively adsorb $F$, researchers have impregnated rare earth elements on various carrier materials, such as La on chitosan beads ${ }^{15}$ and $\mathrm{Zr}$ on collagen fiber. ${ }^{16}$

However, few studies have paid attention to developing effective adsorbents for simultaneous removal of $\mathrm{As}(\mathrm{V})$ and F. ${ }^{17,18}$ Rather low adsorption capacities for As $(\mathrm{V})(0.9 \mathrm{mg} / \mathrm{g})$ and $F(0.5 \mathrm{mg} / \mathrm{g})$ are reported when goethite are applied to remove coexisting $\mathrm{As}(\mathrm{V})$ and $\mathrm{F}$ in a groundwater sample. ${ }^{17}$ Modified cellulose fibers result in an appreciable decrease of $\mathrm{F}$ removal from 82 to $28 \%$ in the presence of $1 \mathrm{mg} / \mathrm{L} \mathrm{As}{ }^{18} \mathrm{~A}$ fundamental understanding of As and $\mathrm{F}$ adsorption mechanisms at the molecular level should improve our ability to design such a composite adsorbent for simultaneous As and F removal. Arsenic predominantly forms bidentate binuclear inner-sphere surface complexes by ligand exchange with hydroxyl groups at oxide surfaces. ${ }^{11,19}$ Ligand exchange between surface hydroxyl group and $\mathrm{F}$ is also the predominate

Received: September 28, 2011

Accepted: January 11, 2012

Published: January 11, 2012 
F adsorption mechanism. ${ }^{17,20}$ Nevertheless, limited knowledge is available about the local coordination environment of $\mathrm{As}(\mathrm{V})$ surface complexes in the presence of F. The lack of this crucial information may inhibit the design of effective adsorbent for $\mathrm{As}(\mathrm{V})$ and $\mathrm{F}$ simultaneous removal.

The objective of this study was to develop a composite adsorbent with titanium and lanthanum oxides impregnated on granular activated carbon (TLAC) for simultaneous effective removal of $\mathrm{As}(\mathrm{V})$ and $\mathrm{F}$. The effectiveness of TLAC was evaluated using batch experiments with a comparison to commercially available adsorbents. Synchrotron-based X-ray microfluorescence $(\mu$-XRF) was used to study the elemental distribution. The local coordination environments of As and $\mathrm{F}$ obtained with extended X-ray absorption fine structure (EXAFS) spectroscopy and Fourier transform infrared (FTIR) spectroscopy were employed as the molecular-level constraints in surface complexation modeling. The results of the study should further our understanding of simultaneous removal mechanisms of $\mathrm{As}(\mathrm{V})$ and $\mathrm{F}$.

\section{EXPERIMENTAL SECTION}

Materials. All solutions were prepared using analytical grade chemicals and deionized (DI) water (Milli-Q, USA). Sodium arsenate $\left(\mathrm{Na}_{3} \mathrm{AsO}_{4} \cdot 12 \mathrm{H}_{2} \mathrm{O}\right)$, sodium fluoride $(\mathrm{NaF})$, sodium perchlorate $\left(\mathrm{NaClO}_{4}\right)$, titanium sulfate $\left(\mathrm{Ti}\left(\mathrm{SO}_{4}\right)_{2}\right)$, sodium arsenite $\left(\mathrm{NaAsO}_{2}\right)$, and lanthanum nitrate $\left(\mathrm{La}\left(\mathrm{NO}_{3}\right)_{3}\right)$ were obtained from Sinopharm Chemical Reagent Co. Ltd. (China). A Suwannee River Humic Acid standard II $(\mathrm{ZS} 101 \mathrm{H})$ was obtained from the International Humic Substances Society (IHSS) and was used as received. GAC $(20 \times 40$ mesh) was obtained from Kaibiyuan Trade Co. Ltd. (China). Granular $\mathrm{Al}_{2} \mathrm{O}_{3}$ with a diameter of $1-3 \mathrm{~mm}$ (Keyuan, China), E33p (Adedge Tech., Inc., USA), titanium dioxide (Yili, China), and lanthanum oxide (Guangfu, China) were used in the experiment without further purification. The stock solutions of $1,000 \mathrm{mg} / \mathrm{L} \mathrm{As}(\mathrm{V}), \mathrm{As}(\mathrm{III})$, and $\mathrm{F}$ were prepared by dissolving $\mathrm{Na}_{3} \mathrm{AsO}_{4} \cdot 12 \mathrm{H}_{2} \mathrm{O}, \mathrm{NaAsO}_{2}$, and $\mathrm{NaF}$ in DI water, respectively, and stored in refrigerator at $4{ }^{\circ} \mathrm{C}$. A background electrolyte of $0.04 \mathrm{M} \mathrm{NaClO}_{4}$ was used in the experiments.

TLAC Synthesis. The TLAC was prepared by impregnating Ti and La oxides on GAC. GAC was boiled for $30 \mathrm{~min}$, then washed with DI water, and dried at $104.5^{\circ} \mathrm{C}$. About $12.0 \mathrm{~g}$ of cleaned GAC were added in $40 \mathrm{~mL}$ of $187.1 \mathrm{~g} / \mathrm{L} \mathrm{Ti}\left(\mathrm{SO}_{4}\right)_{2}$ solution and sonicated for $4 \mathrm{~h}$ before drying at $104.5^{\circ} \mathrm{C}$. The obtained material was transferred into $40 \mathrm{~mL}$ of $467.9 \mathrm{~g} / \mathrm{L} \mathrm{La}\left(\mathrm{NO}_{3}\right)_{3}$ solution and sonicated for another $4 \mathrm{~h}$ to impregnate La. Then, TLAC was roasted at $400{ }^{\circ} \mathrm{C}$ for $6 \mathrm{~h}$, washed with DI water three times, and dried at $104.5{ }^{\circ} \mathrm{C}$. The details of the TLAC optimization are shown in the Supporting Information, and the properties of $\mathrm{E} 33 \mathrm{p}, \mathrm{Al}_{2} \mathrm{O}_{3}$, and TLAC are shown in Table $\mathrm{S} 1$ in the Supporting Information.

Characterization. The surface morphology was examined using a Hitachi S-3000N scanning electron microscope (SEM) with an Oxford energy dispersive X-ray (EDX) analyzer. The BET surface area was determined using an automated surface area analyzer (Micromeritics ASAP 2000). X-ray powder diffraction (XRPD) data were recorded on a Rigaku D/Max-2500 diffractometer at $40 \mathrm{kV}, 100 \mathrm{~mA}$ using a Cutarget tube and a graphite monochromator. Scans were made in the $2 \theta$ range of $5^{\circ}$ to $70^{\circ}$ with a step size of $0.01^{\circ}$ and a count time of $2 \mathrm{~s}$ per step. The analyses of the XRPD patterns were performed using the PDF-2 reference database from the International Center for Diffraction Data database.

Batch Adsorption Experiments. Kinetic experiments were carried out by reacting $30 \mathrm{mg} / \mathrm{L} \mathrm{As}(\mathrm{V})$ and $10 \mathrm{mg} / \mathrm{L} \mathrm{F}$ in $0.04 \mathrm{M}$ $\mathrm{NaClO}_{4}$ solution with $1 \mathrm{~g} / \mathrm{L}$ of TLAC. The suspension was mechanically agitated for $24 \mathrm{~h}$ in the dark at $\mathrm{pH}$ 7.0. At designed time intervals, the samples were passed through a $0.45-\mu \mathrm{m}$ membrane filter for dissolved $\mathrm{As}(\mathrm{V})$ and $\mathrm{F}$ analyses. The speciation and concentration of As were determined using a high-performance liquid chromatography coupled with atomic fluorescence spectrometry
(HPLC-AFS, Jitian, China). Separation of As compounds was carried out in a Hamilton PRP-X100 anion exchange column, using $10 \mathrm{mM}$ phosphate buffer at $\mathrm{pH} 5.8$ as the mobile phase with $1.0 \mathrm{~mL} / \mathrm{min}$ flow rate. The $\mathrm{F}$ concentration was measured using Allzarin Complexone method $^{21}$ with a $\mathrm{HACH} \mathrm{DR} / 2800$ spectrophotometer.

Adsorption isotherm experiments were conducted by transferring $100 \mathrm{~mL}$ solution into each tube containing $0.1 \mathrm{~g}$ of TLAC, E33p, and $\mathrm{Al}_{2} \mathrm{O}_{3}$. The solution contained increasing amounts of $\mathrm{As}(\mathrm{V})$ and $\mathrm{F}$ at $\mathrm{pH} 7$ with $0.04 \mathrm{M} \mathrm{NaClO}_{4}$ as ionic strength. The suspension was mixed on a rotator for $24 \mathrm{~h}$.

To compare the adsorption efficiency of TLAC, E33p, and $\mathrm{Al}_{2} \mathrm{O}_{3}$ for real contaminated groundwater, we $\backslash$ conducted batch adsorption experiments in triplicate for each adsorbent with $1 \mathrm{~h}$ mixing. Groundwater with $0.73 \mathrm{mg} / \mathrm{L} \mathrm{As}(\mathrm{III}), 0.69 \mathrm{mg} / \mathrm{L} \mathrm{As}(\mathrm{V}), 2.01 \mathrm{mg} / \mathrm{L}$ $\mathrm{F}$, and $7.5 \mathrm{mg} / \mathrm{L}$ TOC at $\mathrm{pH} 8.0$ was obtained from a tubewell in Shanxi, China. Synthetic groundwater samples containing $1.7 \mathrm{mg} / \mathrm{L}$ As(III), $3.5 \mathrm{mg} / \mathrm{L} \mathrm{As}(\mathrm{V}), 10 \mathrm{mg} / \mathrm{L} \mathrm{F}$, and $2.5 \mathrm{mg} / \mathrm{L} \mathrm{HA}$ in $0.04 \mathrm{M}$ $\mathrm{NaClO} 4$ at $\mathrm{pH} 7.0$ were used as a comparison. The HA concentration was determined by UV spectroscopy at $\lambda=245 \mathrm{~nm}$.

Adsorption envelope experiments were performed to determine the adsorption edge, which is the percentage of $\mathrm{As}(\mathrm{V})$ and $\mathrm{F}$ adsorbed as a function of the final solution $\mathrm{pH}$. Suspension samples containing 1 and $30 \mathrm{mg} / \mathrm{L} \mathrm{As}(\mathrm{V}), 10 \mathrm{mg} / \mathrm{L} \mathrm{F}$, and $1 \mathrm{~g} / \mathrm{L}$ TLAC were adjusted to desired $\mathrm{pH}$ values in the range of $4-12$ with $\mathrm{NaOH}$ and $\mathrm{HClO}_{4}$. The samples were mixed on a rotator for $24 \mathrm{~h}$.

$\boldsymbol{\mu}$-XRF Analyses. The $\mu$-XRF sample was prepared with $30 \mathrm{mg} / \mathrm{L}$ $\mathrm{As}(\mathrm{V}), 50 \mathrm{mg} / \mathrm{L} \mathrm{F}$, and $1 \mathrm{~g} / \mathrm{L}$ TLAC in $0.04 \mathrm{M} \mathrm{NaClO}_{4}$. The spent TLAC adsorbent was freeze-dried and deposited onto Kapton tape. The monochromator was set at $14 \mathrm{keV}$ to collect $\mu$-XRF maps at beamline $15 \mathrm{U}$ at Shanghai Synchrotron Radiation Facility (SSRF), China. The beam was $5 \times 5 \mu \mathrm{m}^{2}$, the dwell time per pixel was $0.3 \mathrm{~s}$, and the step size was $5 \mu \mathrm{m}$. The peak intensities for As, $\mathrm{Ti}$, and $\mathrm{La}$ were collected at each pixel of $\mu$-XRF maps with $0.4 \times 0.4 \mathrm{~mm}^{2}$ in size.

EXAFS Analysis. The EXAFS samples were prepared using the same batch adsorption method with $30 \mathrm{mg} / \mathrm{L}$ As $(\mathrm{V})$, increasing amounts of $\mathrm{F}$ up to $1000 \mathrm{mg} / \mathrm{L}$ at $\mathrm{pH}$ 7. The spent TLAC media was sealed between two layers of Kapton tape, and analyzed on beamline $14 \mathrm{~W} 1$ at SSRF, China. An energy range of -200 to $1000 \mathrm{eV}$ from the $\mathrm{K}$-edge of As $(11,867 \mathrm{eV})$ was used to acquire the spectra. The spectra were collected in fluorescence mode using a Lytle detector positioned at $90^{\circ}$ to the incident beam, and the sample was at a $45^{\circ}$ angle to the detector. The EXAFS spectra were analyzed using the method as described in our previous reports ${ }^{11,22}$ and detailed in the Supporting Information.

ATR-FTIR Study. Infrared spectra were collected with a Nicolet 6700 FTIR spectrometer equipped with a horizontal $45^{\circ} \mathrm{ZnSe}$ crystal as an attenuated total reflectance (ATR) attachment (Pike Technologies, USA). Spectra were obtained at a resolution of 2 $\mathrm{cm}^{-1}$ with coaddition of 1000 scans using a liquid $\mathrm{N}_{2}$ cooled mercurycadmium-telluride (MCT) detector.

The adsorption samples for FTIR analysis were prepared by mixing $\mathrm{As}(\mathrm{V})$ and $\mathrm{F}$ solution containing $0.04 \mathrm{M} \mathrm{NaCl}$ with $30 \mathrm{~g} / \mathrm{L}$ TLAC at $\mathrm{pH} 7.0$ for $24 \mathrm{~h}$. Then the solid and the solution were separated by centrifuging at $8,000 \mathrm{rpm}$, and the supernatant was filtered through a $0.22-\mu \mathrm{m}$ membrane to remove any residual solid particles. Infrared spectra of adsorbed species of As(V) and F on TLAC were obtained by measuring wet paste and the corresponding supernatant as reference. The spectrum of blank TLAC was also collected as a control. The sample on the $\mathrm{ZnSe}$ crystal was covered with a lid to prevent water evaporation during the measurement. The subtraction of supernatant spectra from the wet paste spectra should yield the spectra of adsorbed $\mathrm{As}(\mathrm{V})$ and $\mathrm{F}$ on TLAC. The baseline correction of the ATR-FTIR spectra was performed without manipulating the magnitude of the peak or peak position shift.

Surface Complexation Modeling. A charge distribution multisite complexation (CD-MUSIC) model was used to describe the adsorption edges of $\mathrm{As}(\mathrm{V})$ and $\mathrm{F}$ on TLAC. The CD-MUSIC has previously been employed to describe As adsorption behavior on $\mathrm{TiO}_{2}{ }^{11}$ and $\mathrm{F}$ adsorption on goethite. ${ }^{20}$ Details of CD-MUSIC modeling are reported in the Supporting Information. 


\section{RESULTS AND DISCUSSION}

Adsorbent Characterization. The SEM images of GAC and TLAC are presented in Figure 1. Compared with the
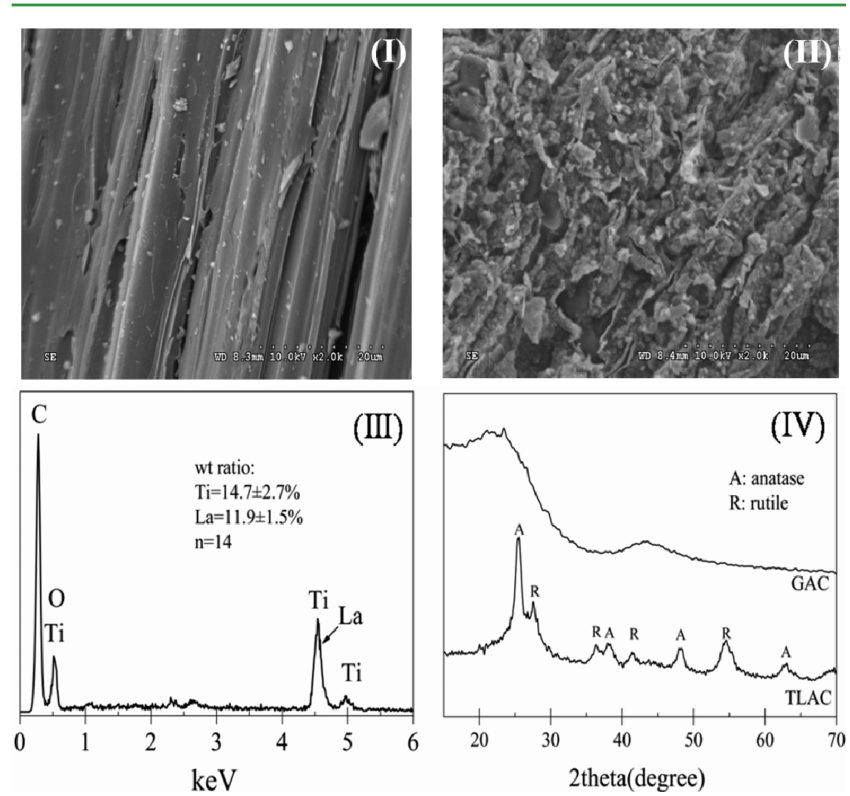

Figure 1. SEM images of pristine (I) GAC and (II) TLAC, (III) EDX spectrum for TLAC with inset showing an average $\mathrm{Ti}$ and $\mathrm{La}$ content at 14 various locations, and (IV) the XRD patterns of GAC and TLAC.

pristine GAC, TLAC exhibited even distribution of metal oxide particles in the porous structure and on the coarse surface. The EDX analysis of 14 different locations on TLAC suggested that the $\mathrm{Ti}$ and $\mathrm{La}$ contents were $14.7 \pm 2.7 \%$ and $11.9 \pm 1.5 \%$, respectively, on a weight basis. In agreement with a previous report, the XRD pattern of GAC showed two broad peaks at $2 \theta$ $=24$ and $43^{\circ}$, attributing to the activated carbon structure (Figure 1IV). ${ }^{23}$ The XRD analysis indicated that the impregnated $\mathrm{Ti}$ oxide existed as a mixture of anatase and rutile. However, no crystalline phase of La compound was observed in TLAC, suggesting that the impregnated La oxide was in amorphous $\mathrm{LaOOH}$ form. When $\mathrm{La}\left(\mathrm{NO}_{3}\right)_{3}$ was used as a precursor, $\mathrm{La}_{2} \mathrm{O}_{3}$ could not be produced until the calcination temperature reached $650{ }^{\circ} \mathrm{C}^{24}$ The results of control experiments detailed in the Supporting Information confirmed that $\mathrm{LaOOH}$ was not transferred to $\mathrm{La}_{2} \mathrm{O}_{3}$ at $400{ }^{\circ} \mathrm{C}$. The BET surface area was slightly reduced from 681 of GAC to $538 \mathrm{~m}^{2} / \mathrm{g}$ of TLAC because the impregnation of $\mathrm{Ti}$ and La oxides may block some porous structure of GAC.

Simultaneous Adsorption of $\mathrm{As}(\mathrm{V})$ and $\mathrm{F}$ on TLAC, E33p, and $\mathrm{Al}_{2} \mathrm{O}_{3}$. Adsorption isotherms of $\mathrm{As}(\mathrm{V})$ and $\mathrm{F}$ (Figure 2) followed Langmuir equation: $C_{\mathrm{e}} / q_{\mathrm{e}}=1 / q_{\mathrm{m}} b+C_{\mathrm{e}} / q_{\mathrm{e}}$, where $C_{\mathrm{e}}(\mathrm{mg} / \mathrm{L})$ is the equilibrium concentration of $\mathrm{As}(\mathrm{V})$ or $\mathrm{F}$, and $q_{\mathrm{e}}(\mathrm{mg} / \mathrm{g}$ adsorbent $)$ is the amount of $\mathrm{As}(\mathrm{V})$ or $\mathrm{F}$ adsorbed; $q_{\mathrm{m}}(\mathrm{mg} / \mathrm{g})$ and $b(\mathrm{~L} / \mathrm{mg})$ are fitting parameters representing the maximum adsorption capacity and the adsorption affinity constant, respectively. The parameters of Langmuir isotherms for TLAC, E33p, and $\mathrm{Al}_{2} \mathrm{O}_{3}$ are listed inTable S2 in the Supporting Information. The maximum adsorption capacities of single $\mathrm{As}(\mathrm{V})(30.3 \mathrm{mg} / \mathrm{g})$ and $\mathrm{F}(27.8$ $\mathrm{mg} / \mathrm{g}$ ) on TLAC were significantly higher than those on E33p (18.0 mg-As/g and $2.3 \mathrm{mg}-\mathrm{F} / \mathrm{g}$ ) and $\mathrm{Al}_{2} \mathrm{O}_{3}$ (7.3 mg-As/g and $4.8 \mathrm{mg}-\mathrm{F} / \mathrm{g})$. With the coexistence of $\mathrm{As}(\mathrm{V})$ and $\mathrm{F}$, the maximum adsorption capacity of As $(\mathrm{V})$ on TLAC decreased from 30.3 to $25.1 \mathrm{mg} / \mathrm{g}$ (a reduction of $17 \%$ ), and that of $\mathrm{F}$ from 27.8 to $17.0 \mathrm{mg} / \mathrm{g}$ (a reduction of $39 \%$ ). The observed unequal decrease in $\mathrm{As}(\mathrm{V})$ and $\mathrm{F}$ adsorption capacity suggested that $\operatorname{As}(V)$ had a higher surface affinity than F.

The TLAC media exhibited a pronounced advantage over E33p, $\mathrm{Al}_{2} \mathrm{O}_{3}$, and the modified cellulose fibers ${ }^{18}$ in $\mathrm{As}(\mathrm{V})$ and $\mathrm{F}$ removal on a weight basis (see Table S2 in the Supporting Information). The $\mathrm{As}(\mathrm{V})$ adsorption on $\mathrm{E} 33 \mathrm{p}$ and $\mathrm{Al}_{2} \mathrm{O}_{3}$ did not significantly decrease in the presence of $\mathrm{F}$ (Figure 2), whereas the $\mathrm{F}$ adsorption in the presence of $\mathrm{As}(\mathrm{V})$ decreased by $64 \%$ (from 2.3 to $0.8 \mathrm{mg}$ of $\mathrm{F} / \mathrm{g}$ ) on E33p and $25 \%$ (from 4.8 to $3.6 \mathrm{mg}$ of $\mathrm{F} / \mathrm{g}$ ) on $\mathrm{Al}_{2} \mathrm{O}_{3}$ (see Table $\mathrm{S} 2$ in the Supporting Information). Modified cellulose fibers could achieve $27.93 \mathrm{mg}$ of As/g and $8.59 \mathrm{mg}$ of $\mathrm{F} / \mathrm{g}$ adsorption capacity. ${ }^{18}$ TLAC resulted in much higher adsorption capacities of $\mathrm{As}(\mathrm{V})$ and $\mathrm{F}$ (see Table S2 in the Supporting Information).

Particle size is an important factor in adsorption. For example, the size effect of $\mathrm{TiO}_{2}$ on As adsorption has been previously reported by $\mathrm{Xu}$ and Meng, ${ }^{25}$ and they found the adsorption capacity of $\mathrm{TiO}_{2}$ for As increased linearly with the BET surface area, which is inversely related to the particle size. As shown in Table S2 in the Supporting Information, the direct comparison of adsorbed $\mathrm{As}(\mathrm{V})$ quantities per $\mathrm{m}^{2}$ surface area of various adsorbents indicated that E33p had the highest surfacearea-based adsorption capacity. Because TLAC was a composite adsorbent with GAC as the supporting material for $\mathrm{TiO}_{2}$ and
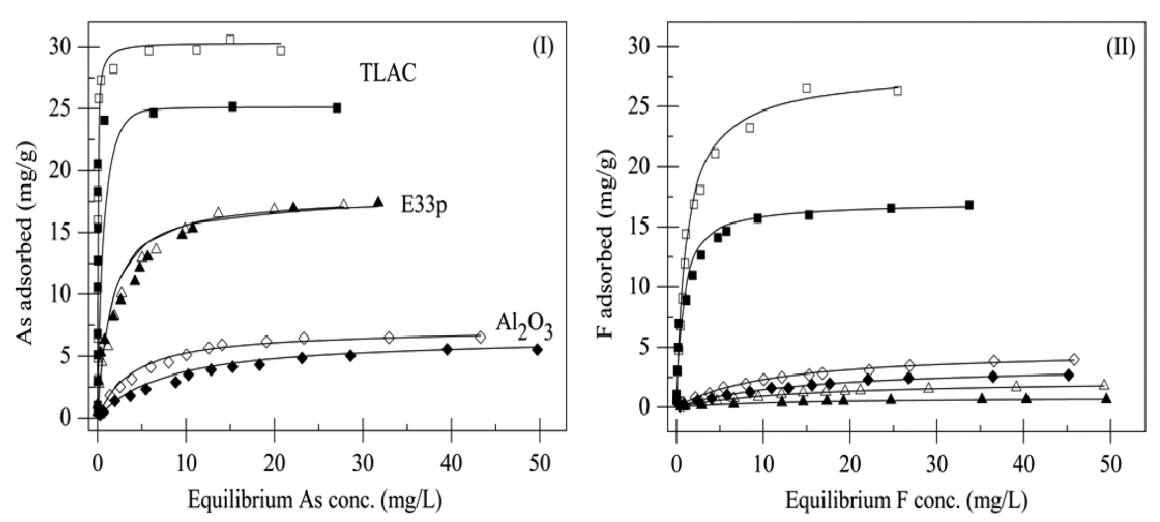

Figure 2. Adsorption isotherms for (I) As(V) and (II) F on TLAC (square), E33p (triangle), and $\mathrm{Al}_{2} \mathrm{O}_{3}$ (diamond) in $0.04 \mathrm{M} \mathrm{NaClO}_{4}$ solution at $\mathrm{pH}$ 7.0. Open and closed symbols represent the presence of single adsorbate and coexisting $\mathrm{As}(\mathrm{V})$ and $\mathrm{F}$, respectively. 
$\mathrm{LaOOH}$, its BET surface area was mainly attributed to pristine GAC. GAC with its superior surface area, however, did not contribute to $\mathrm{As}(\mathrm{V})$ adsorption as indicated in Figure S1 in the Supporting Information. This observation may suggest that surface area is an important parameter when comparing the adsorption capacity of the same material with various sizes. Nevertheless, the surface area alone may not be a proper parameter to compare different media because the adsorption mechanisms may not be the same for various adsorbents.

In this study, the adsorption capacity of As $(30.3 \mathrm{mg} / \mathrm{g})$ on TLAC was comparable with that on nanocrystalline $\mathrm{TiO}_{2}(37.5$ $\mathrm{mg} / \mathrm{g}$ ) reported in a previous study under the same experimental condition where $\mathrm{As}(\mathrm{V})$ in a $0.04 \mathrm{M}$ electrolyte solution was adsorbed on $1 \mathrm{~g} / \mathrm{L} \mathrm{TiO}_{2}$ at $\mathrm{pH} 7{ }^{26}$ The particle size and aggregation state of impregnated $\mathrm{TiO}_{2}$ on TLAC should be more stable during the adsorption process than that of nanocrystalline $\mathrm{TiO}_{2}$. The different physical states of TLAC and nanocrystalline $\mathrm{TiO}_{2}$ may lead to the discrepancies in As adsorption capacity.

The effectiveness of TLAC, E33p, and $\mathrm{Al}_{2} \mathrm{O}_{3}$ on simultaneous As and $\mathrm{F}$ removal was compared using synthetic and real contaminated groundwater samples and the results are shown in Figure 3. TLAC was superior to the commercial media in the

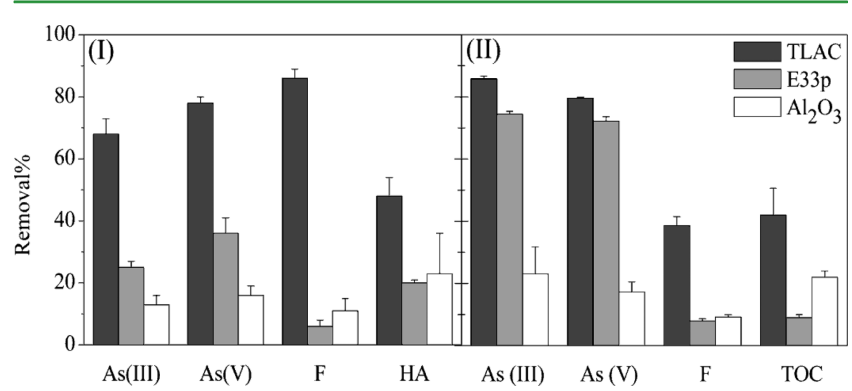

Figure 3. Adsorption efficiency using $1 \mathrm{~g} / \mathrm{L}$ TLAC, E33p, and $\mathrm{Al}_{2} \mathrm{O}_{3}$ (I) for a synthetic water sample containing $1.7 \mathrm{mg} / \mathrm{L} \mathrm{As}(\mathrm{III}), 3.5 \mathrm{mg} /$ $\mathrm{L} \mathrm{As}(\mathrm{V}), 10 \mathrm{mg} / \mathrm{L} \mathrm{F}$, and $2.5 \mathrm{mg} / \mathrm{L} \mathrm{HA}$ in $0.04 \mathrm{M} \mathrm{NaClO}_{4}$ at $\mathrm{pH} 7.0$, and (II) for a real groundwater sample containing $0.73 \mathrm{mg} / \mathrm{L} \mathrm{As}(\mathrm{III})$, $0.69 \mathrm{mg} / \mathrm{L} \mathrm{As}(\mathrm{V}), 2.01 \mathrm{mg} / \mathrm{L} \mathrm{F}$, and $7.5 \mathrm{mg} / \mathrm{L}$ TOC at $\mathrm{pH}$ 8.0.

removal of As (III), As(V), and F in synthetic samples even at elevated contamination levels (Figure 3I). The same conclusion can be drawn using real groundwater samples (Figure 3II). Over $80 \% \mathrm{As}(\mathrm{V})$ and $\mathrm{As}(\mathrm{III})$ was adsorbed on TLAC, which was the highest removal efficiency among the three media. To compare the removal efficiency of TLAC with commercial media, $1 \mathrm{~g} / \mathrm{L}$ adsorbent was used in batch adsorption experiments. In the practice of water treatment, the adsorptive filtration process is generally adopted where contaminated water flow through the media in a fixed bed. ${ }^{27}$ The enhanced solid to liquid ratio in the filter house could provide sufficient surface sites for adsorption, resulting in satisfactory water quality.

The $\mathrm{F}$ adsorption in groundwater sample was reduced compared with that in synthetic water (Figure 3). The groundwater sample had a complex matrix including $110 \mathrm{mg} /$ L sulfate and $412 \mathrm{mg} / \mathrm{L}$ carbonate, which can have a negative impact on $\mathrm{F}$ adsorption. ${ }^{28}$ Sulfate can form both outer-sphere and inner-sphere complexes on metal oxides, ${ }^{29}$ whereas carbonate primarily forms inner-sphere surface complex. ${ }^{30}$ Therefore, the competition from the coexisting anions would compete with As and F for the available adsorption sites. ${ }^{31}$ The adverse effect was much more pronounced for $\mathrm{F}$ than for As, indicating As has a higher affinity to adsorbent than F. In addition, no soluble $\mathrm{La}$ and $\mathrm{Ti}$ was detected in solution, suggesting that $\mathrm{LaOOH}$ and $\mathrm{TiO}_{2}$ would not leach out during the adsorption.

Adsorption Kinetics of $A s(V)$ and $F$ on TLAC. The adsorption rates of $A s(V)$ and $F$ were rapid during the initial 15 min, and the $A s(V)$ and $F$ concentration kept relatively constant thereafter (Figure 4). A pseudosecond-order kinetics model has been applied previously to describe the adsorption of As $(\mathrm{V})$ on $\mathrm{TiO}_{2}{ }^{26}$ and $\mathrm{F}$ on lanthanum hydroxide ${ }^{32}$ and was used in the present study. The equation is expressed as $t / q_{t}=t /$ $q_{\mathrm{e}}+1 / k q_{\mathrm{e}}^{2}$, where $\mathrm{q}_{t}$ and $q_{\mathrm{e}}$ are the amount $(\mathrm{mg} / \mathrm{g})$ of $\mathrm{As}(\mathrm{V})$ or $\mathrm{F}$ adsorbed at time $t$ and equilibrium, respectively, and $\mathrm{k}(\mathrm{g} /$ $(\mathrm{mg} \mathrm{h}))$ is the rate constant. The model described the experimental data pretty well (Figure 4) with calculated parameters shown in Table S3 in the Supporting Information. $\mathrm{F}$ had a negligible effect on As(V) adsorption kinetics. Although the equilibration time of $\mathrm{F}$ adsorption was not affected by the presence of $\mathrm{As}(\mathrm{V})$, the adsorption capacity of $\mathrm{F}$ decreased from 9.4 to $7.4 \mathrm{mg} / \mathrm{g}$ with coexisting $\mathrm{As}(\mathrm{V})$. This observation also confirmed a higher affinity of As(V) to TLAC than F.

Element Distribution on TLAC. The SEM-EDX (see Figure S4 in the Supporting Information) and $\mu$-XRF (Figure 5) analyses of spent TLAC media showed that As(V) was associated with the impregnated $\mathrm{Ti}$ and La oxides. The highly correlated $\mathrm{Ti}$ and $\mathrm{La}$ demonstrated that $\mathrm{TiO}_{2}$ and $\mathrm{LaOOH}$ were evenly impregnated on GAC in $\mu \mathrm{m}$ size resolution provided by $\mu$-XRF. To investigate our hypothesis that $\mathrm{As}(\mathrm{V})$ and $\mathrm{F}$ adsorb on $\mathrm{TiO}_{2}$ and $\mathrm{LaOOH}$, respectively, the molecular level study including EXAFS and FTIR should be performed.
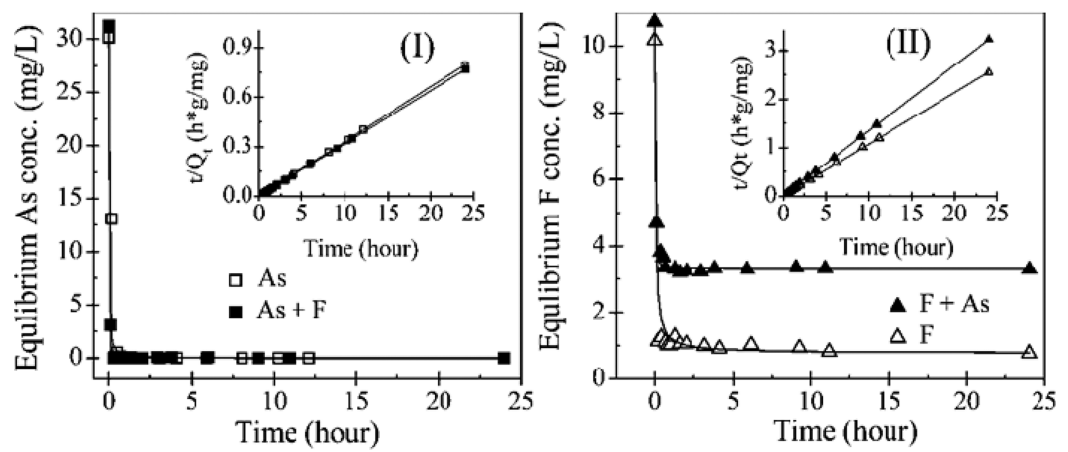

Figure 4. Adsorption kinetics of (I) $30 \mathrm{mg} / \mathrm{L} \mathrm{As}$ (V) and (II) $10 \mathrm{mg} / \mathrm{L} \mathrm{F}$ on TLAC in $0.04 \mathrm{M} \mathrm{NaClO} 4$ solution at pH 7.0. Open and closed symbols represent the presence of single adsorbate and coexisting As and $\mathrm{F}$, respectively. 

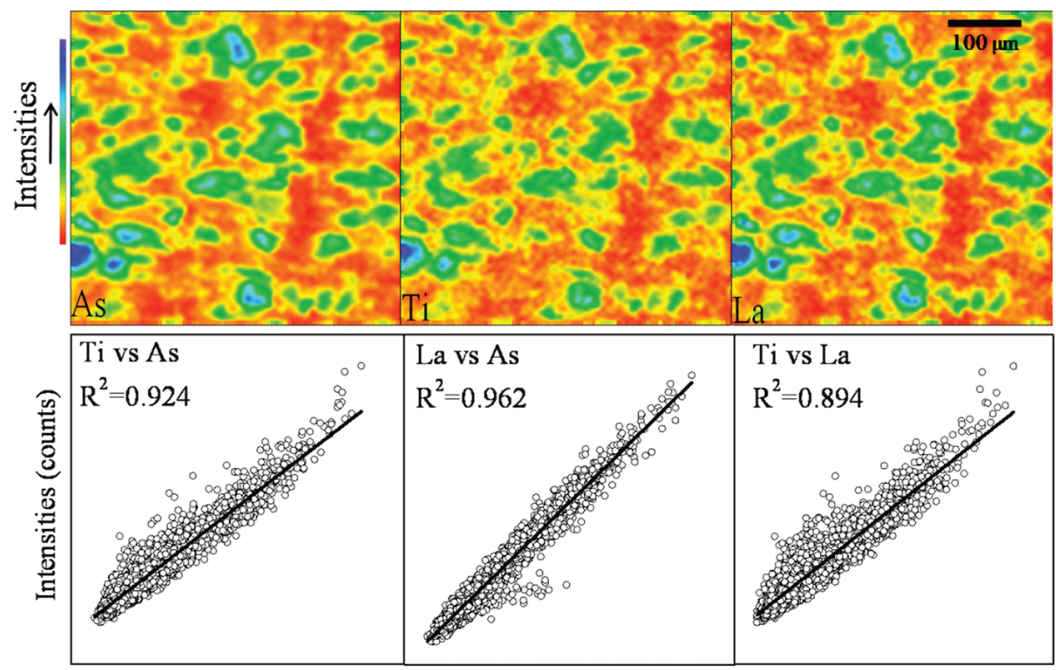

Intensities (counts)

Figure 5. $\mu$-XRF analyses of spent TLAC adsorbed with $30 \mathrm{mg} / \mathrm{L} \mathrm{As}(\mathrm{V})$ and $50 \mathrm{mg} / \mathrm{L} \mathrm{F}$ in $0.04 \mathrm{M} \mathrm{NaClO}_{4}$ at $\mathrm{pH}$ 7. The upper row shows the $\mu$ XRF map of As, $\mathrm{Ti}$, and $\mathrm{La}$ in a $0.4 \times 0.4 \mathrm{~mm}^{2}$ size; the lower row presents the correlations of $\mathrm{As}$, $\mathrm{Ti}$, and $\mathrm{La}$.

Arsenic K-edge EXAFS Analysis. EXAFS spectroscopy was employed to determine the As(V) local coordination environment on TLAC in the presence of increasing amounts of F. The $k^{3}$-weighted EXAFS spectra and Fourier transform (FT) versus radial distance are shown in Figure 6. The optimal
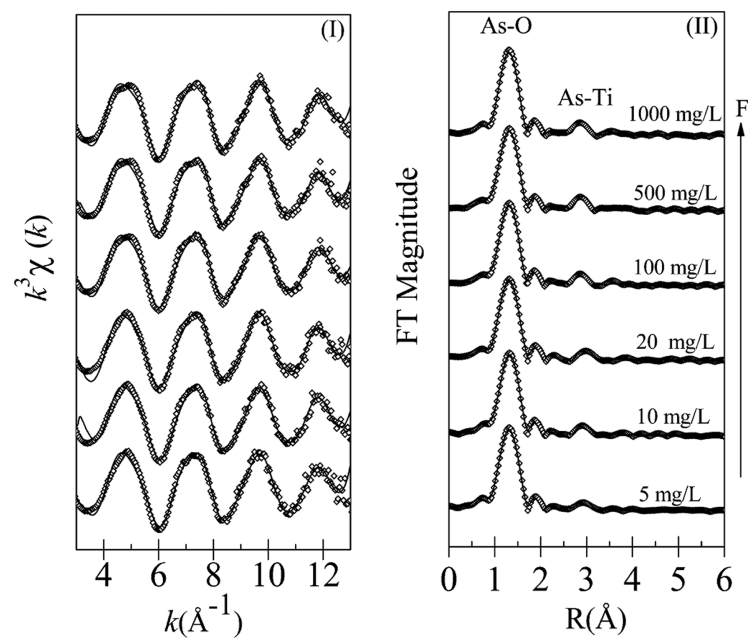

Figure 6. Normalized $k^{3}$-weighted observed (diamond line) and model calculated (solid line) (I) As K-edge EXAFS, and (II) the corresponding magnitude of Fourier transform ( $x$-axis not corrected for phase shifts) spectra for spent TLAC under increasing concentrations of $\mathrm{F}$.

structure parameters obtained by fitting the theoretical paths to the experimental spectra are shown in Table S4 in the Supporting Information. The FT of the EXAFS spectra isolated the contributions of coordination shells, and the peak positions correspond to the interatomic distances. However, these peak positions in Figure 6 were uncorrected for the phase shift, so they deviated from the true distance by $0.3-0.5 \AA$.

The EXAFS analysis showed that the first and strongest peak in the FT curve was contributed by 4 oxygen atoms at an average distance of $1.69 \AA$ for all samples, which is in agreement with previous reports. ${ }^{22,33,34}$ The result confirmed that the tetrahedral $\mathrm{AsO}_{4}$ structure did not change under the competition of F. The second peak in the FT was attributed to $1.3-1.6 \mathrm{Ti}$ atoms at an interatomic distance of $3.33-3.35 \AA$. In line with our previous study, ${ }^{11}$ the As-Ti distances and coordination numbers suggested that $\mathrm{As}(\mathrm{V})$ formed bidentate binuclear inner-sphere complexes on $\mathrm{TiO}_{2}$. In the presence of $\mathrm{F}$ with a concentration up to $1000 \mathrm{mg} / \mathrm{L} \mathrm{F}(\mathrm{F} / \mathrm{As}=131$, molar ratio), the structure of adsorbed $\mathrm{As}(\mathrm{V})$ remained unchanged.

ATR-FTIR Analysis. In order to understand which metal oxide is responsible for F adsorption, the ATR-FTIR spectra of adsorbed $\mathrm{As}(\mathrm{V})$ and $\mathrm{F}$ were collected as shown in Figure 7. All

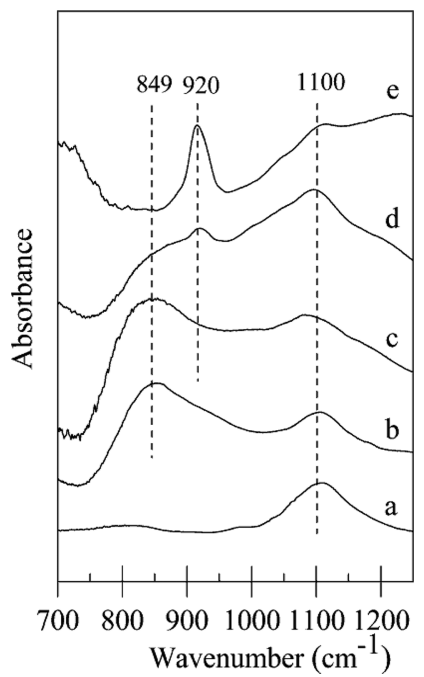

Figure 7. ATR-FTIR difference spectra of (a) pristine TLAC, and spent TLAC with (b) $0.01 \mathrm{M} \mathrm{As}(\mathrm{V})$, (c) $0.01 \mathrm{M} \mathrm{As}(\mathrm{V})$ and $0.26 \mathrm{M}$ $\mathrm{NaF}$, (d) $0.01 \mathrm{M} \mathrm{As}(\mathrm{V})$ and $0.65 \mathrm{M} \mathrm{NaF}$, and (e) $0.8 \mathrm{M} \mathrm{NaF}$.

spectra exhibited a broad peak at around $1100 \mathrm{~cm}^{-1}$ which can be attributed to TLAC. In the presence of $0.01 \mathrm{M} \mathrm{As}(\mathrm{V})$ (Figure 7-b), a strong peak at $849 \mathrm{~cm}^{-1}$ was observed that corresponded to the As-O vibration. ${ }^{35}$ With the addition of 0.26 and $0.65 \mathrm{M} \mathrm{F}$, this As-O peak did not shift. The lack of change in $\mathrm{As}(\mathrm{V})$ peak position under an extremely high $\mathrm{F} /$ 
As $(\mathrm{V})$ molar ratio of 65 indicates that $\mathrm{F}$ may be adsorbed to a different surface site other than $\mathrm{TiO}_{2}$. Single $\mathrm{F}$ adsorption resulted in a peak at $920 \mathrm{~cm}^{-1}$ (Figure $7 \mathrm{e}$ ).

To further validate the assumption that $\mathrm{F}$ selectively adsorbed on $\mathrm{LaOOH}$, we compared the $\mathrm{F}$ adsorption on TLAC, $\mathrm{LaOOH}, \mathrm{La}_{2} \mathrm{O}_{3}, \mathrm{TiO}_{2}$, and GAC. Less than $5 \% \mathrm{~F}$ was adsorbed on GAC and $\mathrm{TiO}_{2}$ (Figure 8). In stark contrast,

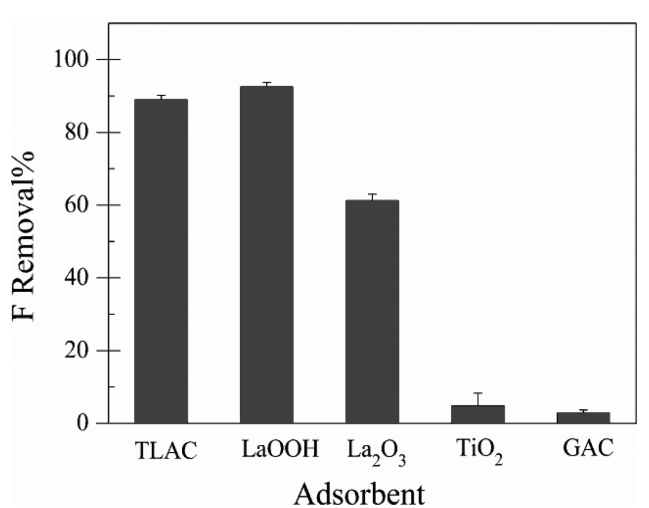

Figure 8. Adsorption percentage of $25 \mathrm{mg} / \mathrm{L} \mathrm{F}$ on different adsorbents in $0.04 \mathrm{NaClO} 4$ at $\mathrm{pH} 7.0$.

$\mathrm{LaOOH}$ and TLAC resulted in more than $89 \% \mathrm{~F}$ adsorption, indicating that $\mathrm{F}$ preferentially adsorbed on $\mathrm{LaOOH}$ surfaces. TLAC resulted in a higher $\mathrm{F}$ removal than $\mathrm{La}_{2} \mathrm{O}_{3}$, most probably because the amorphous $\mathrm{LaOOH}$ in TLAC may have a larger BET surface area than that crystal form of $\mathrm{La}_{2} \mathrm{O}_{3}$.

Surface Complexation Modeling. To link the macroscopic $\mathrm{As}(\mathrm{V})$ and $\mathrm{F}$ adsorption behaviors with the molecular level adsorption mechanisms, we employed a CD-MUSIC model to simulate the $\mathrm{As}(\mathrm{V})$ and $\mathrm{F}$ adsorption $\mathrm{pH}$ edges. The model adopted $\mathrm{TiOH}$ surface for $\mathrm{As}(\mathrm{V})$ adsorption and $\mathrm{LaOH}$ surface for $F$.

Two As(V) concentration levels, 1 and $30 \mathrm{mg} / \mathrm{L}$, were used to study the effect of $10 \mathrm{mg} / \mathrm{L} \mathrm{F}$ competition. The results showed that over 90\% $\mathrm{As}(\mathrm{V})$ was adsorbed in environmental relevant $\mathrm{pH}$ range of 5 to 9 for low and high initial As $(\mathrm{V})$ concentrations (Figure 9). The adsorption percentage at $\mathrm{pH}>$ 10 was decreased due to the competitive adsorption with hydroxides, ${ }^{11}$ and a higher initial $\mathrm{As}(\mathrm{V})$ concentration resulted in a greater decrease in adsorption. $\mathrm{F}$ had negligible effect on As $(\mathrm{V}) \mathrm{pH}$ edge curves.

The adsorption percentage of $\mathrm{F}$ increased slightly from $81.5 \%$ at $\mathrm{pH} 3.24$ to $91.2 \%$ at $\mathrm{pH} 5.35$, and then decreased slowly to $15.1 \%$ at $\mathrm{pH} 11.1$ (Figure 9II). This observation is consistent with $\mathrm{F}$ adsorption on metal oxides and metalimpregnated adsorbents. ${ }^{16,36,37}$ The adsorption of $\mathrm{F}$ decreased with the addition of $\mathrm{As}(\mathrm{V})$, and the decrease was evident with increasing $\mathrm{As}(\mathrm{V})$ concentrations from 1 to $30 \mathrm{mg} / \mathrm{L}$. The zeta potential of the double layer on surface would decrease appreciably to negative values in environmental $\mathrm{pH}$ range upon As $(\mathrm{V})$ adsorption. ${ }^{11}$ As a consequence, $\mathrm{F}$ adsorption would be inhibited. On the other hand, $\mathrm{F}$ adsorption by ligand exchange of a surface $\mathrm{OH}^{-}$by $\mathrm{F}^{-}$suggests that the charge and potential of the surface should not change upon $\mathrm{F}$ adsorption. Therefore, $\mathrm{F}$ adsorption caused negligible changes in $\mathrm{As}(\mathrm{V})$ adsorption. If the adsorbents were mixed with $\mathrm{TiO}_{2}$ impregnated $\mathrm{GAC}$ and $\mathrm{LaOOH}$ impregnated GAC, coexisting $\mathrm{As}(\mathrm{V})$ and $\mathrm{F}$ would also compete for the surface hydroxyl groups because this ligand exchange is the mechanism of adsorption of anions.

\section{CONCLUSION}

Highly efficient simultaneous As and $\mathrm{F}$ adsorptive media is under urgent need to reduce the coexposure risks. Our results show that TLAC has a higher As(V) and $\mathrm{F}$ adsorption capacity than that of widely used $\mathrm{E} 33 \mathrm{p}$ and $\mathrm{Al}_{2} \mathrm{O}_{3}$ media, and could be used as an effective adsorbent for simultaneous removal of As $(\mathrm{V})$ and $\mathrm{F}$. $\mathrm{TiO}_{2}$ and $\mathrm{LaOOH}$ evenly distributed on the surfaced of the TLAC, which preferably form inner-sphere surface complexes with $\mathrm{As}(\mathrm{V})$ and $\mathrm{F}$, respectively. In addition, the advantage of GAC in removing dissolved organic matter makes TLAC more attractive. Applicability of TLAC for longterm real groundwater treatment merits further investigation.

\section{ASSOCIATED CONTENT}

\section{Supporting Information}

Description of TLAC optimization and characterization, $\mathrm{LaOOH}$ synthesis and PZC determination, SEM-EDX, and EXAFS analysis; tables showing comparison of media, parameters for isotherms, kinetics, EXAFS, and CD-MUSIC modeling. This material is available free of charge via the Internet at http://pubs.acs.org.

\section{AUTHOR INFORMATION}

\section{Corresponding Author}

*E-mail: cyjing@rcees.ac.cn.

\section{ACKNOWLEDGMENTS}

We acknowledge the financial support of the National Natural Science Foundation of China (20977098, 20890112,

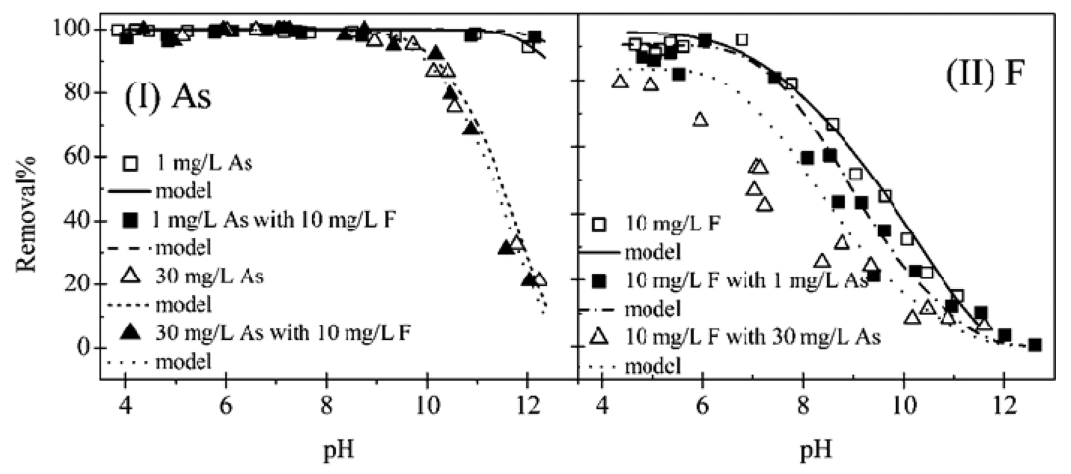

Figure 9. Experimental (symbols) and CD-MUSIC model calculations (lines) of (I) As(V) and (II) F pH adsorption edges on $1 \mathrm{~g} / \mathrm{L}$ TLAC in 0.04 $\mathrm{M} \mathrm{NaClO} 4$. 
20921063) and the National Basic Research Program of China (2010CB933502).

\section{REFERENCES}

(1) Smedley, P. L.; Kinniburgh, D. G. Appl. Geochem. 2002, 17, 517568.

(2) Nordstrom, D. K. Science 2002, 296, 2143-2145.

(3) Amini, M.; Mueller, K.; Abbaspour, K. C.; Rosenberg, T.; Afyuni, M.; Moller, K. N.; Sarr, M.; Johnson, C. A. Environ. Sci. Technol. 2008, 42, 3662-3668.

(4) Smedley, P. L.; Nicolli, H. B.; Macdonald, D. M. J.; Barros, A. J.; Tullio, J. O. Appl. Geochem. 2002, 17, 259-284.

(5) Smedley, P. L.; Zhang, M.; Zhang, G.; Luo, Z. Appl. Geochem. 2003, 18, 1453-1477.

(6) Armienta, M. A.; Segovia, N. Environ. Geochem. Health 2008, 30, 345-353.

(7) Farooqi, A.; Masuda, H.; Firdous, N. Environ. Pollut. 2007, 145, 839-849.

(8) Mittal, M.; Flora, S. J. S. Drug Chem. Toxicol. 2007, 30, 263-281.

(9) Rocha-Amador, D.; Navarro, M. E.; Carrizales, L.; Morales, R.; Calderon, J. Cadernos De Saude Publica 2007, 23, S579-S587.

(10) Guidelines for Drinking-Water Quality. , 2nd ed.; World Health Organization: Geneva, Switzerland, 1993; Vol. 1: Recommendations.

(11) Pena, M.; Meng, X. G.; Korfiatis, G. P.; Jing, C. Y. Environ. Sci. Technol. 2006, 40, 1257-1262.

(12) Fan, X.; Parker, D. J.; Smith, M. D. Water Res. 2003, 37, 49294937.

(13) Luo, T.; Cui, J. L.; Hu, S.; Huang, Y. Y.; Jing, C. Y. Environ. Sci. Technol. 2010, 44, 9094-9098.

(14) Gu, Z. M.; Fang, J.; Deng, B. L. Environ. Sci. Technol. 2005, 39, 3833-3843.

(15) Viswanathan, N.; Meenakshi, S. J. Colloid Interface Sci. 2008, $322,375-383$.

(16) Liao, X. P.; Shi, B. Environ. Sci. Technol. 2005, 39, 4628-4632.

(17) Tang, Y. L.; Wang, J. M.; Gao, N. Y. J. Environ. Sci. China 2010, 22, 1689-1694.

(18) Tian, Y.; Wu, M.; Liu, R.; Wang, D.; Lin, X.; Liu, W.; Ma, L.; Li, Y.; Huang, Y. J. Hazard. Mater. 2011, 185, 93-100.

(19) Liu, S. Q.; Jing, C. Y.; Meng, X. Q. Sci. Total Environ. 2008, 392, 137-144.

(20) Hiemstra, T.; Van Riemsdijk, W. H. J. Colloid Interface Sci. 2000, 225, 94-104.

(21) Clesceri, L. S. G., A., E. Eaton, A. D., Standard Methods for the Examination of Water and Wastewater, 20th ed.; American Public Health Association: Washington, D.C., 1998.

(22) Jing, C. Y.; Liu, S. Q.; Patel, M.; Meng, X. G. Environ. Sci. Technol. 2005, 39, 5481-5487.

(23) Gao, X. A.; Liu, S. J.; Zhang, Y.; Luo, Z. Y.; Cen, K. F. J. Hazard. Mater. 2011, 188, 58-66.

(24) Mekhemer, G. A. H.; Balboul, B. A. A. Colloids Surf., A 2001, $181,19-29$.

(25) Xu, Z. H.; Meng, X. G. J. Hazard. Mater. 2009, 168, 747-753.

(26) Pena, M. E.; Korfiatis, G. P.; Patel, M.; Lippincott, L.; Meng, X. G. Water Res. 2005, 39, 2327-2337.

(27) Jing, C. Y.; Meng, X. G.; Calvache, E.; Jiang, G. B. Environ. Pollut. 2009, 157, 2514-2519.

(28) Tang, Y. L.; Guan, X. H.; Wang, J. M.; Gao, N. Y.; McPhail, M. R.; Chusuei, C. C. J. Hazard. Mater. 2009, 171, 774-779.

(29) Peak, D.; Ford, R. G.; Sparks, D. L. J. Colloid Interface Sci. 1999, 218, 289-299.

(30) Bargar, J. R.; Kubicki, J. D.; Reitmeyer, R.; Davis, J. A. Geochim. Cosmochim. Acta 2005, 69, 1527-1542.

(31) Meng, X. G.; Bang, S.; Korfiatis, G. P. Water Res. 2000, 34, $1255-1261$.

(32) Na, C. K.; Park, H. J. J. Hazard. Mater. 2010, 183, 512-520.

(33) Sherman, D. M.; Randall, S. R. Geochim. Cosmochim. Acta 2003, $67,4223-4230$.
(34) Jing, C. Y.; Meng, X. G.; Liu, S. Q.; Baidas, S.; Patraju, R.; Christodoulatos, C.; Korfiatis, G. P. J. Colloid Interface Sci. 2005, 290, 14-21.

(35) Myneni, S. C. B.; Traina, S. J.; Waychunas, G. A.; Logan, T. J. Geochim. Cosmochim. Acta 1998, 62, 3499-3514.

(36) Raichur, A. M.; Basu, M. J. Sep. Purif. Technol. 2001, 24, 121127.

(37) Sujana, M. G.; Thakur, R. S.; Rao, S. B. J. Colloid Interface Sci. 1998, 206, 94-101. 